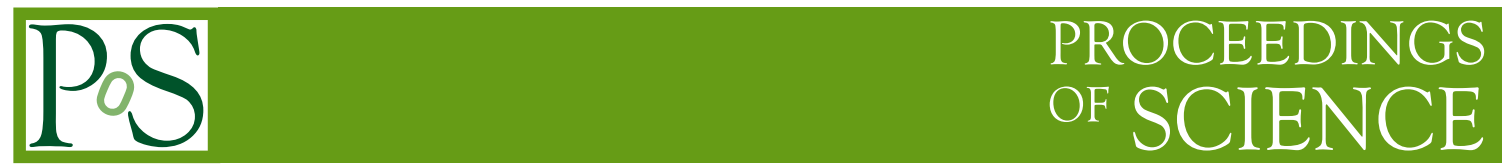

\title{
Neutrino pathways to cosmology
}

\section{Jose W.F Valle*}

Instituto de Física Corpuscular

E-mail: valle.ificegmail.com

The theoretical and phenomenological status of neutrino physics is reviewed as well as the cosmological implications for dark matter, inflation and the baryon asymmetry.

Frontiers of Fundamental Physics 14 - FFP14,

15-18 July 2014

Aix Marseille University (AMU) Saint-Charles Campus, Marseille

${ }^{*}$ Speaker. 